\title{
A análise do conteúdo equações de primeiro grau em edi- ções da Avaliação da Aprendizagem em Processo
}

\author{
Gladys Beatriz Churata \\ Garcia (1)
}

Escola Estadual Rafael Orsi Filho Sorocaba/SP

Đyanghwa33@gmail.com

Paulo Cesar Oliveira (D)

Universidade Federal de São Carlos

Đpaulooliveira@ufscar.br

\author{
Content analysis 1st degree equations in Process Learning \\ Evaluation editions
}

\section{Abstract}

This text analyzed the mathematical content 'First degree equation' and Systems of linear equations 'contained in an external or large scale evaluation system, consolidated in schools in the state public network of São Paulo; in this case, the Evaluation of Learning in Process - AAP. The theoretical support of this research was based on the contributions of the semiotic representation records in the analysis of the understanding of mathematical concepts. The research developed from a qualitative perspective in the modality of documentary research, as it involves material that has not received an analytical treatment. Eight questions were selected from various editions of this external evaluation system, from 2012 to 2018 . The analysis of the mathematical content of these questions took into account two categories: identification of records of semiotic representation in the approach of the mathematical contents cited and the comparison of skills proposals in the AAP questions in relation to the Teacher's Notebook and the Process Evaluation Matrix for the AAP editions. The results of the research revealed that there is a convergence in skills when confronted with the three documentary sources. In relation to the semiotic representation records, the questions included the presence of the records in mother tongue, figural, algebraic, numerical and graphic, typical of the study of these mathematical contents. There was also the cognitive activity of transforming the semiotic representations of the treatment and the conversion between records, which enabled the analysis of the semantic congruence and non-congruence phenomena.

Key words: Semiotics; Large-Scale Evaluation; 1st Degree Equation; Systems of Linear Equations; Documentary Research.

\section{Resumo}

Este texto analisou os conteúdos matemáticos 'Equação de primeiro grau' e Sistemas de equações lineares' contidos em um sistema de avaliação externa ou de larga escala, consolidado em escolas da rede pública estadual de São Paulo; no caso, a Avaliação da Aprendizagem em Processo - AAP. O suporte teórico dessa pesquisa, pautou-se nas contribuições dos registros de representação semiótica na análise da compreensão de conceitos matemáticos. A pesquisa desenvolveu sob a perspectiva qualitativa na modalidade de pesquisa documental, por envolver um material que não recebeu um tratamento analítico. Foram selecionadas oito questões de várias edições desse sistema de avaliação externa, no período de 2012 a 2018. A análise do conteúdo matemático dessas questões levou em conta duas categorias: identificação dos registros de representação semiótica na abordagem dos conteúdos matemáticos citados e a comparação das habilidades propostas nas questões da AAP em relação ao Caderno do Professor e a Matriz de Avaliação Processual para as edições da AAP. Os resultados da pesquisa revelaram que há convergência nas habilidades quando confrontadas as três fontes documentais. Em relação aos registros de representação semiótica, as questões contemplaram a presença dos registros em língua materna, figural, algébrico, numérico e gráfico, próprios do estudo desses conteúdos matemáticos. Ocorreu também a atividade cognitiva de transformação das representações semióticas do tratamento e da conversão entre registros, o que possibilitou a análise dos fenômenos da congruência e da não congruência semântica.

Palavras-chave: Semiótica; Avaliação em Larga Escala; Equação do Primeiro Grau; Sistemas de Equações Lineares; Pesquisa Documental. 


\section{INTRODUÇÃO}

Historicamente, o governo federal criou em 1990, o Sistema de Avaliação da Educação Básica -Saeb, um instrumento de gestão das políticas educacionais e como interesse subjacente a elas, a qualidade de ensino avaliada pela mensuração do desempenho dos estudantes.

O Saeb, inicialmente aplicado nos atuais segundo, quarto, sexto e oitavo anos do Ensino Fundamental envolvendo conteúdos de Língua portuguesa e Matemática, tinha como objetivo a verificação da leitura e resolução de problemas dos estudantes. No entanto, a demora na divulgação dos resultados do Saeb; o seu caráter amostral e a necessidade de promover avaliações anuais, já que esse sistema de avaliação era aplicado a cada dois anos, constituíram fatores motivadores para que os estados brasileiros planejassem seus próprios sistemas de avaliação em larga escala [8].

Em 1998 foi disponibilizado pelo Ministério da Educação aos professores dos anos finais do Ensino Fundamental os Parâmetros Curriculares Nacionais. Nesse documento já foi possível encontrar registros sobre os efeitos da consolidação do Saeb em meados da década de 90, revelando indicadores expressivos de como se encontra o ensino de Matemática:

As provas de Matemática aplicadas em 1993, pelo Sistema Nacional de Avaliação Escolar da Educação Básica (SAEB) indicavam que, na primeira série do ensino fundamental, $67,7 \%$ dos alunos acertavam pelo menos metade dos testes. Esse índice caía para qual 17,9\% na terceira série, tornava a cair para $3,1 \%$, na quinta série e subia para 5,9\% na sétima série. Nas provas de Matemática, aplicadas em 1995, abrangendo alunos de quartas e oitavas séries do ensino fundamental, os percentuais de acerto por série/grau e por capacidades cognitivas, além de continuar diminuindo à medida que aumentavam os anos de escolaridade, indicavam também que as maiores dificuldades encontravam-se nas questões relacionadas à aplicação de conceitos e à resolução de problemas [1] (p. 23-24).

O Saeb constituiu-se em uma máquina propulsora de sistemas de avaliação de larga escala que proliferou nas políticas públicas estaduais e municipais, os quais foram criando instrumentos próprios de avaliação. De acordo com [9] (p. 76), "a avaliação torna-se sistemática, orgânica, adquire um caráter regulador e ganha centralidade nas discussões educacionais. Deixa de ser possível, atualmente, imaginar processos educativos que não conduzam a modalidades de julgamentos". Neste sentido, tornase relevante a pesquisa em educação envolvendo a análise de fatores e implicações sobre os sistemas de avaliação externa ou de larga escala.

[5] contemplou em sua pesquisa especificamente o Sistema Mineiro de Avaliação da Educação Pública (SIMAVE) por meio da abordagem qualitativa bibliográfica, que 
envolveu 28 dissertações de mestrado e 5 teses de doutorado, desenvolvidas, em sua maioria, em programas nacionais de Pós-Graduação em Educação, no período de 2000 a 2013.

Para o repertório das pesquisas catalogadas por [5] elaboramos a 'tabela 1' que apresenta o número de dissertações por área de conhecimento e suas respectivas temáticas:

Tabela 1: Mapeamento das pesquisas sobre o SIMAVE

\begin{tabular}{|l|c|l|}
\hline Área de conhecimento & Quantidade & \multicolumn{1}{c|}{ Temática } \\
\hline Educação & 26 & Política pública, gestão e avaliação educacional \\
\hline Política social & 1 & Estado, política social e cidadania \\
\hline Economia & 1 & Estatística socioeconômica \\
\hline Administração & 2 & $\begin{array}{l}\text { Administração pública e gestão de sistemas } \\
\text { educacionais }\end{array}$ \\
\hline Linguística & 2 & $\begin{array}{l}\text { Ensino e aprendizagem de línguas e linguística } \\
\text { aplicada }\end{array}$ \\
\hline $\begin{array}{l}\text { Ensino de ciências e } \\
\text { matemática }\end{array}$ & 1 & Educação matemática \\
\hline
\end{tabular}

Fonte: adaptado de [5]

O único trabalho em educação matemática catalogado por [5] foi o de [20], inserido no campo de pesquisa da história da educação matemática, mais especificamente, investigar as transformações que vêm ocorrendo na disciplina Matemática, da terceira série do Ensino Médio, a partir da constituição do SIMAVE/Proeb no ano de 2000.

Os resultados da pesquisa de [20] apontam para uma interferência no currículo da disciplina, no momento em que os resultados da avaliação do SIMAVE são parâmetros para o recebimento de uma premiação instituída pelo governo de Minas Gerais para que as escolas alcançassem metas que variam ano após ano. O que está em jogo é o processo de bonificação, sobre o qual os professores acabam sendo pressionados pelos colegas da escola, em função desse prêmio ser balizado a partir dos resultados das avaliações dos conteúdos Matemática e Língua Portuguesa do SIMAVE/Proeb.

Numa pesquisa mais recente [10], um montante de 17 teses e dissertações brasileiras defendidas no período de 2001 a 2017, foi submetido à análise, com foco nas implicações dos conteúdos matemáticos contidos em sistemas de avaliação externa. Mais especificamente, esses autores trabalharam com pesquisas que, por um lado, envolveram a observação dos estudantes enquanto realizadores dos exames e suas implicações, análise de indicativos de desempenho dos estudantes, bem como concepção de professores sobre conteúdo específico aplicado nos exames. Por outro lado, houve pesquisas que [10] identificaram como problema de pesquisa a análise da composição da prova, ou seja, a matriz curricular que contém as habilidades e competências presentes nas provas e que implicações podem trazer para o ensino de matemática. 
O relato de pesquisa que propomos descrever articula-se a este último subgrupo de pesquisas, no qual temos como propósito analisar o conteúdo matemático de questões extraídas de edições da Avaliação de Aprendizagem em Processo - AAP, um sistema de avaliação em larga escala aplicado nas escolas públicas estaduais de São Paulo.

A motivação por essa linha de pesquisa foi em virtude da necessidade da primeira autora na busca de um referencial teórico para subsidiar a intervenção pedagógica em sala de aula, de modo a contribuir tanto na aprendizagem do aluno quanto no desempenho em avaliações externas como a AAP. Como mestranda no Programa de Pós-Graduação no Ensino de Ciências Exatas da UFSCar houve a oportunidade de estudar sobre a Teoria dos Registros de Representação Semiótica - RRS e compreender suas potencialidades quanto às dificuldades inerentes ao aprendizado do aluno.

Naquele momento da vida acadêmica, atuava como professora efetiva em uma escola da rede pública do Estado de São Paulo e a cobrança por melhorias no Índice de Desenvolvimento da Educação do Estado de São Paulo - IDESP era grande. O IDESP é um indicador de qualidade das etapas escolares dos anos do Ensino Fundamental e Ensino Médio. Como o desempenho na avaliação externa é crucial no cálculo desse índice, tinha como pressuposto que a análise do professor sobre o conteúdo exposto nesse tipo de avaliação possibilitaria repensar sobre o processo ensino-aprendizagem de conteúdos matemáticos.

Na condição de professora responsável por turmas de oitavo ano do Ensino Fundamental, o estudo de equações permeava dois bimestres letivos, um fator importante na delimitação do conteúdo matemático para análise na AAP. Em síntese, a análise do conteúdo matemático nesse sistema de avaliação em larga escala foi conduzido considerando, por um lado, outras duas fontes documentais, o material apostilado intitulado 'Caderno do Professor' e a Matriz de Avaliação Processual [18] para a composição das habilidades da AAP. Por outro lado, utilizamos a Teoria dos Registros de Representação Semiótica na análise das questões selecionadas com o propósito de compreensão matemática dos conteúdos em estudo, ou seja, 'Equação do $1^{\circ}$ grau' e 'Sistemas de equações lineares'.

\section{MATERIAL APOSTILADO PARA AS ESCOLAS PÚBLICAS ESTADUAIS DE SÃo PAULO}

O Caderno do Professor e o Caderno do Aluno são materiais apostilados criados pelo programa São Paulo Faz Escola, complementares ao Currículo Oficial do Estado de São Paulo [11], vigente até o ano de 2018.

Cada volume do Caderno do Professor contém: 
ensino dos conteúdos disciplinares específicos e a aprendizagem dos alunos. Esses conteúdos, habilidades e competências são organizados por série/ano e acompanhados de orientações para a gestão da aprendizagem em sala de aula e para a avaliação e recuperação. Oferecem também sugestões de métodos e estratégias de trabalho para as aulas, experimentações, projetos coletivos, atividades extraclasse e estudos interdisciplinares [11] (p. 8).

No Caderno do Aluno são apresentadas as aulas conforme o conteúdo do Caderno do Professor, contendo as tarefas, textos complementares, indicadores bibliográficos, dicas de estudo e revisão.

O conteúdo 'Equação do primeiro grau' é abordado na primeira Situação de Aprendizagem do segundo volume do Caderno do professor para o oitavo ano do Ensino Fundamental, tomando por base as seguintes competências e habilidades: leitura e interpretação de enunciados e transposição entre as linguagens escrita e algébrica. No que diz respeito à avaliação da aprendizagem, uma orientação dada ao professor é que o mesmo prepare o aluno para "[. . . ]uma boa leitura de enunciados e para a transposição de linguagens (do texto para a Álgebra e vice-versa). A leitura e a interpretação de enunciados será melhor quanto mais o aluno puder praticá-la com orientação do professor" [15] (p. 24). Outra recomendação dada ao professor: evite "[. . .] concentrar o curso apenas em problemas do tipo 'resolva a equação...', 'determine o valor de $x$...' etc., sendo preferível que se privilegiem problemas com texto e contexto" [15] (p. 24). De fato, averiguando os exemplos e orientações didático-pedagógicas desse Caderno do Professor encontramos apenas um exemplo do tipo "resolva a equação..." cujo objetivo foi resolver equações mais complexas, no caso, com coeficientes racionais.

Na terceira Situação de Aprendizagem do segundo volume do Caderno do Professor para o oitavo ano do Ensino Fundamental estão contidas as seguintes competências e habilidades: resolver sistemas de equações pelo método da adição e substituição; representar uma equação com duas incógnitas no plano cartesiano; analisar e discutir as possíveis soluções de um sistema linear; interpretar graficamente a solução de um sistema.

Em termos de orientações avaliativas, é desejável que o professor proponha atividades que contemplem os seguintes itens: tarefas que visam à aplicação de procedimentos de resolução dos sistemas lineares, bem como a verificação dos resultados obtidos; representar equações no plano cartesiano e construir tabelas com alguns valores das incógnitas; análise e discussão das soluções de um sistema linear; identificar quando o sistema linear é possível e determinado, indeterminado ou impossível.

\section{AVALIAÇÃO DE APRENDIZAGEM EM PROCESSO - AAP}


A Avaliação da Aprendizagem em Processo é uma ação desenvolvida de modo colaborativo entre a Coordenadoria de Gestão da Educação Básica, a Coordenadoria de Informação, Monitoramento e Avaliação Educacional e um grupo de Professores Coordenadores das Oficinas Pedagógicas de diferentes Diretorias de Ensino do Estado de São Paulo, que visa avaliar os componentes curriculares de Língua Portuguesa e Matemática. A prova de Matemática é composta por questões objetivas de múltipla escolha e questões abertas, com base no que é prescrito no Currículo do Estado de São Paulo [11] para as escolas públicas estaduais.

O propósito desta avaliação é o acompanhamento da aprendizagem das turmas e alunos de forma individualizada, com um caráter diagnóstico. Tem como objetivo apoiar as unidades escolares e os docentes na elaboração de estratégias adequadas a partir da análise de seus resultados, buscando a melhoria do desempenho dos alunos, especialmente nas ações de recuperação contínua.

Implantada, como piloto, em agosto de 2011, sua primeira edição, teve como foco o sexto ano do Ensino Fundamental e a primeira série do Ensino Médio.

Em 2012, ocorreu a segunda e terceira edição em cada um dos semestres letivos, as quais ampliou sua abrangência e passou a contemplar o sexto é sétimo ano do Ensino Fundamental e a primeira e segunda série do Ensino Médio.

No ano de 2013, ocorreu a quarta e quinta edição, uma em cada semestre letivo. Sua ampliação contemplou todos os anos do Ensino Fundamental e as séries do Ensino Médio. O mesmo processo se repetiu para os anos de 2014 (sexta e sétima edição) e 2015 (oitava e nona edição). A partir de 2016 houve duas mudanças na estrutura da AAP: a periodicidade de aplicação para os anos finais do Ensino Fundamental e as séries do Ensino Médio passou de cada início de semestre para o início dos três primeiros bimestres letivos. A outra novidade foi a implantação desse sistema de avaliação para os anos iniciais do Ensino Fundamental. Neste sentido, no período de 2016 a 2019, houve a $10^{a}$ edição até a 24ª edição desse sistema de avaliação externa.

Até a oitava edição, além da formulação dos instrumentos de avaliação, na forma de cadernos de provas para os alunos, também foram elaborados documentos específicos de orientação para os professores, os chamados 'Comentários e Recomendações Pedagógicas', que continham o quadro de habilidades, gabaritos, itens, interpretação pedagógica das alternativas, sugestões de atividades subsequentes às análises dos resultados, orientação para aplicação e correção das produções textuais.

A partir da $9^{a}$ edição ( $2^{\circ}$ semestre de 2015$)$ até a $24^{a}$ edição ( $3^{\circ}$ bimestre de 2019$)$, além da formulação dos instrumentos de avaliação, na forma de cadernos de provas para os alunos, também foram elaborados os cadernos do professor, um material com 
orientações específicas para os docentes, quadro de habilidades de cada prova, exemplar da prova, gabarito, grade de correção e recomendações pedagógicas gerais. Em relação aos anos iniciais do Ensino Fundamental, tal material é acrescido de instruções para a aplicação da prova e orientações para correção das mesmas.

Com base na Matriz de Avaliação Processual, a qual contém "[ . . ] as competências e habilidades que devem ser desenvolvidos ao longo do percurso escolar, destacando as que orientarão a elaboração das provas da Avaliação da Aprendizagem em Processo - AAP" [18] (p. 8), apresentamos informações sobre os temas equação de $1^{\circ}$ grau e sistemas de equações lineares.

As competências e habilidades que norteiam as edições da AAP são estabelecidas em relação ao conteúdo das Situações de Aprendizagem do Caderno do Professor, mais especificamente no caso desse relato de pesquisa, o segundo volume desse material apostilado para o $8^{\circ}$ ano do Ensino Fundamental. No caso do conteúdo 'Equação do primeiro grau' o estudante deve ser capaz de "[. . .] relacionar uma expressão matemática a uma expressão na língua materna e vice-versa" [18] (p. 28).

Na terceira Situação de Aprendizagem, o conteúdo 'Sistemas de equações lineares' o estudante deve ser capaz de "[ . . .] identificar o sistema de equações lineares que resolve um problema; resolver sistemas de equações lineares e interpretar graficamente a solução de um sistema linear" [18] (p. 28).

\section{TEORIA DOS REGISTROS DE REPRESENTAÇÃO SEMIÓTICA}

$\mathrm{Na}$ condição de pensador contemporâneo e investigador da aprendizagem matemática, o filósofo e psicólogo de formação [2, 3] estuda o funcionamento cognitivo do aluno na realização de atividades matemáticas e seus possíveis problemas de aprendizagem.

Segundo [3] não é possível estudar os fenômenos relativos ao conhecimento sem se recorrer à noção de representação. Para ratificar esta afirmação, o autor retoma três momentos historicamente marcantes em que se pressupõe que o conhecimento só possa ser mobilizado por um sujeito a partir de uma atividade de representação.

O primeiro marco diz respeito à representação mental, definida a partir das contribuições de Jean Piaget sobre a teoria do desenvolvimento da inteligência, pautada na oposição entre o plano da ação em pensamento e o plano da representação.

Em meados da década de cinquenta, no século passado, temos o segundo marco: representação interna ou computacional. Neste contexto há uma polarização do método de tratamento da representação, saltando do tempo empregado para a interiorização das ações (perspectiva piagetiana) para o tempo da reação. Trata-se de um período em que a noção de representação torna-se essencial como forma sob a qual 
uma informação pode ser decodificada, a partir do tratamento por meio de um sistema.

A representação semiótica é o último marco e está presente em trabalhos acadêmicos envolvendo a aquisição de conhecimentos matemáticos, bem como os problemas que sua aprendizagem origina. Do contexto geral de semiótica, o signo é relacionado a um objeto concreto. Para a especificidade matemática, o símbolo (signo) representa o objeto abstrato por meio da ação do sujeito do conhecimento (significante ou conceito).

A palavra 'abstrato' diz respeito ao fato de que o objeto matemático não é perceptível, mas seu acesso se dá por meio de representações semióticas. Com efeito, outro argumento se constrói, desta vez em relação ao binômio objeto e representação: "não se pode ter compreensão em matemática, se nós não distinguimos um objeto de sua representação" [3] (p. 14).

As representações gráficas, numérica ou algébrica são consideradas, e usadas, meramente como uma maneira de exteriorização das representações mentais para fins de comunicação. Podemos dizer que esta interpretação é restrita, uma vez que elas desempenham uma finalidade relevante na construção do pensamento matemático.

[2] (p. 13) salienta a importância dos registros de representação para a matemática afirmando que: "o desenvolvimento das representações semióticas foi a condição essencial para a evolução do pensamento matemático". Em outras palavras, a evolução da matemática teve como fundamento para seu desenvolvimento o uso de registros de representação para expressar ideias construídas.

[2] destaca a relevância e o uso das representações semióticas no estudo dos objetos matemáticos, dado que todo pensamento matemático é externalizado por meio de registros de representação, que devem ser examinados a fim de possibilitar a construção do conhecimento, ou seja, os objetos matemáticos não são diretamente perceptíveis ou observáveis sem o uso de registros de representação, como indica a afirmação:

(...) diferentemente dos outros domínios do conhecimento científico, os objetos matemáticos não são jamais acessíveis perceptivelmente ou microscopicamente (microscópio, telescópio, aparelhos de medida, etc.). O acesso aos objetos passa necessariamente por representação semiótica. Além do que, isso explica por que a evolução dos conhecimentos matemáticos conduziu ao desenvolvimento e à diversificação de registros de representação. [2] (p. 21)

Um registro de representação semiótica de um objeto matemático pode ser a língua materna, algébrico, gráfico, numérico, entre outros. [2, 3] afirma que dispor de vários registros de representação semiótica não é suficiente para garantir a compreensão em matemática. É preciso levar em conta as transformações específicas que estes registros de representação semiótica permitem, no caso, o tratamento e a conversão. 
Por fim, é necessário que haja a coordenação das representações semióticas formuladas em registros distintos. Isto implica na ação do sujeito ser capaz de reconhecer a representação semiótica de um mesmo objeto em, pelo menos dois registros distintos.

A transformação de uma representação semiótica de um mesmo objeto matemático em um determinado registro para uma representação semiótica com outro registro é uma atividade cognitiva de conversão. Já o tratamento de uma representação é a transformação da mesma em outra representação tomando por base o mesmo registro.

[7] expôs na 'figura 1' um exemplo das transformações de tratamento envolvendo a representação semiótica do objeto equação do $1^{\circ}$ grau na língua materna e no registro algébrico. A conversão das representações semióticas do mesmo objeto entre registros, no caso a língua materna e o registro algébrico, também é contemplada na 'figura 1':

Figura 1: Transformações de representações semióticas

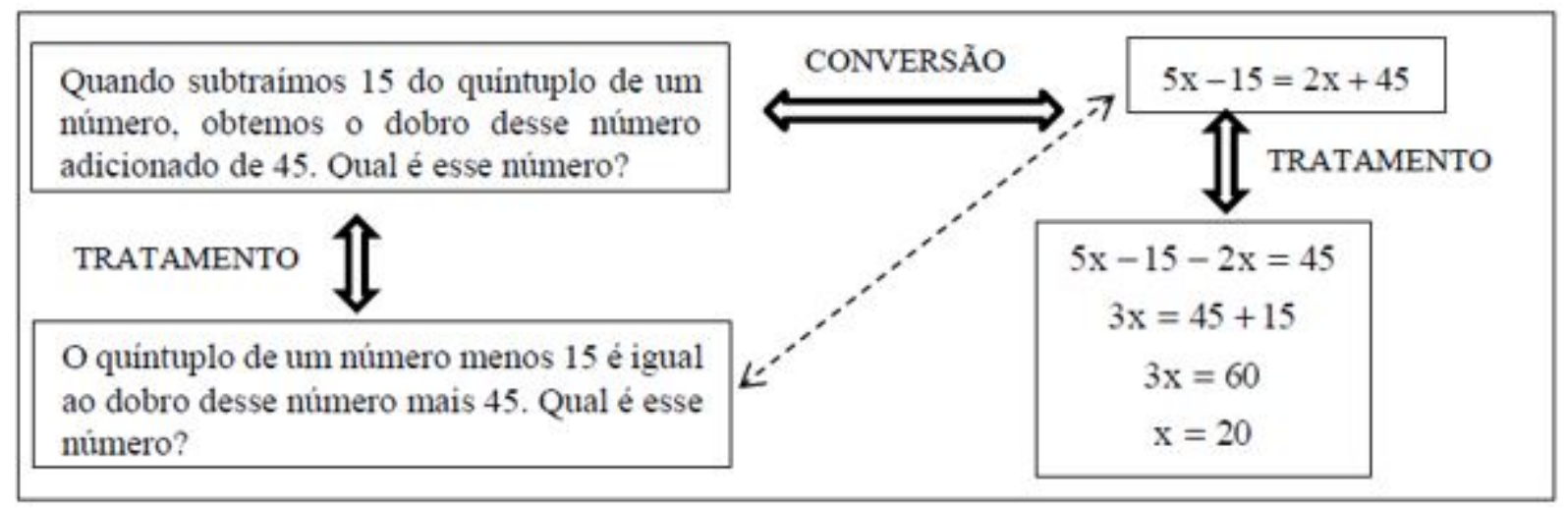

Fonte: [7] (p. 86)

No conteúdo da 'figura 1' utilizamos o símbolo de equivalência também para expressar a conversão das representações semióticas entre os registros língua materna e algébrico, pois não basta que o sujeito conheça o conteúdo de um ou mais registros isoladamente, mas sim que transite entre as mais diversas representações que possui o objeto matemático em questão.

O custo cognitivo deste trânsito depende em muito do que o autor chama de congruência semântica. Sendo que, a esse respeito, destacamos que uma conversão será semanticamente congruente quando a representação final transparecer na representação de partida, o que torna uma atividade relativamente trivial. Enquanto que uma conversão semanticamente não congruente será aquela em que a representação final não transparece na representação de partida. De acordo com tal teoria, o custo cognitivo, quando a conversão é congruente, é menor do que quando a conversão é não congruente.

$[2,3]$ enuncia que para ser congruente, uma conversão deve satisfazer três condi- 
ções:

1.) Correspondência semântica ou correspondência uma a uma, entre os elementos significantes: para cada elemento simples no registro de saída tem um elemento simples no registro de chegada.

2.) Univocidade semântica terminal: cada unidade significante no registro de saída tem uma única unidade no registro de chegada.

3.) A conservação da ordem que compõe cada uma das unidades de significado: diz respeito à forma de apresentação de cada uma das representações.

[7] apresentam por meio de dois exemplos contidos na 'figura 2' um esboço de análise e implicações dos critérios de congruência na conversão de representações semióticas entre registros.

Figura 2: Conversão na representação semiótica

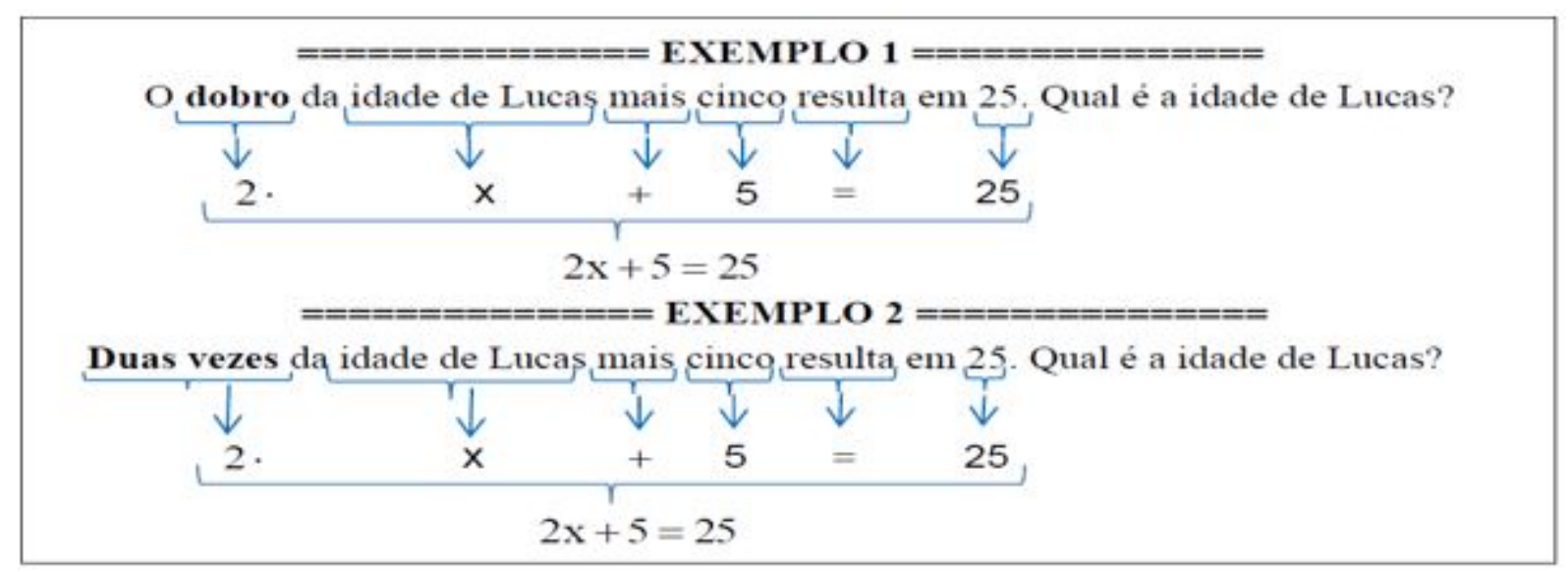

Fonte: $[7](p .87)$

No 'exemplo 1' verificamos que a palavra 'dobro' no registro na língua materna (saída) possui apenas um signo, enquanto que na representação algébrica (chegada) temos o numeral '2' e a operação de multiplicação em correspondência a palavra 'dobro', isto é, dois signos são considerados. Assim, nesse exemplo não há conservação da correspondência semântica das unidades de significado (primeiro critério).

Já no 'exemplo 2' observamos que o mesmo problema, com uma pequena alteração (tratamento) na escrita, permite verificar a correspondência semântica das unidades de significado. Observe que agora a expressão 'duas vezes', que possui dois signos, está em correspondência com '2.' que também possui dois signos considerados.

A univocidade semântica terminal (segundo critério) é conservada em ambos os exemplos. O mesmo ocorre com o terceiro critério, pois é possível verificar que a ordem das unidades significantes nas duas representações, tanto em língua natural 
quanto na representação. Para confrontar com essa ideia, [7] (p. 88) apresentaram o 'exemplo 3' como um contra exemplo para o terceiro critério, reescrevendo o enunciado do 'exemplo 2':

Figura 3: Exemplo relativo à não conservação da ordem das unidades de significado

\section{EXEMPLO 3}

Se adicionarmos um número ao dobro da idade de Lucas, obteremos 25. Qual é a idade Lucas sabendo que o número adicionado foi o cinco?

Fonte: [7] (p. 88)

Nessa reformulação do enunciado original (exemplo 2), é possível verificar que as unidades de significado no registro de partida não estão na mesma ordem que as unidades de significado consideradas na representação algébrica por meio da equação $' 2 x+5=25$ '.

Segundo [3] (p. 69), "[...] esse critério é, sobretudo, importante quando se trata de comparar frases e fórmulas literais". Uma possível dificuldade do aluno pode ser a crença de que para fazer a conversão das representações semióticas entre os registros na língua materna e algébrico é suficiente fazer a tradução das palavras presentes no enunciado na mesma ordem em que elas aparecem. No 'exemplo 3', os alunos podem incorrer no erro de equacionar o problema na forma $2 x=25+5$.

Do que foi abordado nos três exemplos, a medida que mais critérios de congruência não são conservados na conversão das representações semióticas entre registros, maior é o custo cognitivo para fazer essa transformação.

\section{PERCURSO METODOLÓGICO}

A metodologia empregada neste relatório de pesquisa foi qualitativa de natureza documental. "A pesquisa documental vale-se de materiais que não receberam ainda um tratamento analítico, ou que ainda podem ser reelaborados de acordo com os objetivos da pesquisa" [6] (p. 51). O material submetido à análise com base no aporte teórico dos registros de representação semiótica é composto por um conjunto de 8 questões extraídas de algumas edições da Avaliação de Aprendizagem em Processo - AAP, no período de 2012 a 2018.

Este período é justificado pelo fato de que no início de 2018, iniciaram-se as discussões para a elaboração de um novo Currículo oficial para as escolas públicas do Estado de São Paulo.

Cada uma das questões escolhidas e dispostas no 'Quadro 1', é um exemplar do conteúdo 'Equação do primeiro grau' e 'Sistemas de equações lineares', em acordo 
às competências e habilidades estabelecidas tanto no segundo volume do Caderno do Professor para o $8^{\circ}$ ano do Ensino Fundamental, quanto na Matriz de Avaliação Processual para a AAP.

Quadro 1: Distribuições das questões

\begin{tabular}{cclcc}
\hline Ano & Edição & $\begin{array}{l}\text { Período } \\
\text { Letivo }\end{array}$ & Questão & Segmento escolar \\
\hline 2012 & 3 & $2^{\circ}$ semestre & 1 & $1^{\text {a }}$ série do Ensino Médio \\
2012 & 2 & $1^{\text {o }}$ semestre & 4 & $2^{\text {a }}$ série do Ensino Médio \\
2013 & 5 & $2^{\circ}$ semestre & 10 & $1^{\text {a }}$ série do Ensino Médio \\
2014 & 6 & $1^{0}$ semestre & 1 & $9^{\circ}$ ano do Ensino Fundamental \\
2014 & 6 & $1^{0}$ semestre & 10 & $9^{\circ}$ ano do Ensino Fundamental \\
2016 & 13 & $3^{\circ}$ bimestre & 7 & $8^{\circ}$ ano do Ensino Fundamental \\
2018 & 21 & $3^{\circ}$ bimestre & 10 & $8^{\circ}$ ano do Ensino Fundamental \\
2018 & 21 & $3^{\circ}$ bimestre & 11 & $8^{\circ}$ ano do Ensino Fundamental
\end{tabular}

Fonte: Arquivo da pesquisa

A análise ordenada de cada uma das questões listadas no 'Quadro 1', será feita levando em conta duas categorias a priori: identificação dos registros de representação semiótica na abordagem dos conteúdos matemáticos já citados e comparação das habilidades propostas nas questões da AAP em relação ao Caderno do Professor e à Matriz de Avaliação Processual, voltadas para o $8^{\circ}$ ano do Ensino Fundamental.

$\mathrm{Na}$ apresentação do enunciado de cada uma dessas questões optamos por não incluir as respectivas alternativas, dentre as quais, o aluno é orientado a assinalar apenas uma como provável resposta correta.

\subsection{Primeira questão}

O exemplar em análise trata-se da primeira questão da AAP de 2012 formulada para alunos da $1^{\mathrm{a}}$ série do Ensino Médio, conforme conteúdo do 'Quadro 2':

Quadro 2: Análise da primeira questão

Ao repartir uma conta de $R \$ 78,00$ no restaurante AL GEBRÁ, três amigos estabeleceram que: Rui pagaria $3 / 4$ do que Gustavo pagou; Cláudia pagaria $R \$ 10,00$ a menos que a terça parte do que Gustavo pagou. Que valor da conta coube a cada um dos três amigos?

Fonte: [12] (p. 8)

A habilidade requerida nessa questão da AAP foi "resolver problemas envolvendo equação do $1^{\circ}$ grau com coeficientes racionais [12] (p. 8). Em se tratando de um enunciado na forma de problema, é desejável que o aluno seja capaz de fazer a leitura e interpretação do enunciado e estabelecer a transposição entre as linguagens escrita e algébrica, conforme as diretrizes expostas no Caderno do Professor e na Matriz de Avaliação Processual, voltadas para o $8^{\circ}$ ano do Ensino Fundamental.

Em termos de resolução dessa questão, se considerarmos a incógnita ' $x$ ' para a quantia paga por Gustavo, Rui pagou três quartos do que foi pago por Gustavo, ou 
seja, $3 / 4 x$. Claudia pagou $\mathrm{R} \$ 10,00$ a menos que a terça parte do que Gustavo pagou, ou seja, $1 / 3 x-10$. A equação decorrente é dada por: $x+3 / 4 x+1 / 3 x-10=78$.

Na conversão da representação semiótica do registros na língua materna para o algébrico, há conservação da correspondência semântica entre as unidades de significado (primeiro critério de congruência), ou seja, a quantidade de signos de cada uma das unidades significantes do registro de partida corresponde à mesma quantidade signos no registro de chegada. Por exemplo, na expressão 'três quartos do que' há dois signos cuja equivalência referencial algébrica é ' $3 / 4$.', na qual simbolizamos 0 '.' como operador da multiplicação.

A univocidade semântica terminal (segundo critério de congruência) não é válido nessa questão, pois seu enunciado começa com a expressão "ao repartir", a qual indica a ideia de divisão. No entanto, a equivalência referencial dada no registro algébrico utiliza o signo '=', indicando uma igualdade entre o primeiro membro da equação que contém a soma das três parcelas correspondentes ao pagamento da conta de cada um dos três amigos e o segundo membro (total da conta paga).

No que tange à ordem das unidades de significado (terceiro critério de congruência), o mesmo não é conservado na expressão 'pagou $\mathrm{R} \$ 10,00$ a menos que a terça parte do que Gustavo pagou'. Na equivalência referencial, o registro algébrico não segue a ordem das unidades significantes na língua materna, ou seja, ' $3 / 4 x-10$ '.

Em síntese, nessa transformação de conversão há um custo cognitivo maior, devido dois critérios de congruência semântica não serem conservados.

\subsection{Segunda questão}

O exemplar em análise trata-se da quarta questão da AAP de 2012 formulada para alunos da $2^{\mathrm{a}}$ série do Ensino Médio, conforme conteúdo do 'Quadro 3':

Quadro 3: Análise da segunda questão

Numa gincana de Matemática, Hélio calculou mentalmente dois números de modo que sua soma
fosse igual a 12 e sua diferença 2. Lúcia utilizou outra estratégia, determinando esses dois números
algebricamente. Dessa forma, um possível sistema de equações para indicar o raciocínio de Lúcia é:

Fonte: [13] (p. 18)

A habilidade requerida para nessa questão da AAP foi "identificar um sistema de equações do $1^{\circ}$ grau que expressa um problema", o que converge com os propósitos do Caderno do Professor e a Matriz de Avaliação Processual para o $8^{\circ}$ ano do Ensino Fundamental. Pontualmente, no Caderno do Professor, no estudo de sistemas de equações lineares, "o foco da avaliação deve estar na tradução do problema para a linguagem algébrica (montagem do sistema)" [15] (p. 60).

Em termos de resolução de acordo com a habilidade requerida, se designarmos por 
" $x$ " o primeiro número e por " $y$ " o segundo número, a soma registrada na linguagem algébrica é dada por $x+y=12$. Já a diferença é $x-y=2$.

Na conversão da representação semiótica do registro na língua materna para o algébrico, o primeiro critério de congruência não é conservado. No fragmento 'sua diferença 2' temos três signos, porém utilizamos cinco símbolos na representação semiótica do registro de chegada, ou seja, $x-y=2$.

O segundo critério que diz respeito à univocidade semântica terminal, está conservado, pois a palavra 'soma' faz referência ao signo '+' e a palavra "diferença" é referencialmente equivalente ao signo '-'. Com relação ao terceiro critério de congruência, não há conservação da ordem das unidades de significado. Por exemplo, na expressão "a soma de dois números", a conversão dessa representação semiótica para o registro algébrico não se inicia pelo signo '+'. Mesma situação ocorre com a referência para a "diferença" entre esses dois números.

Assim como ocorreu na análise da primeira questão (seção anterior), nessa transformação de conversão há um custo cognitivo maior, devido dois critérios de congruência semântica não serem conservados.

\subsection{Terceira questão}

Apresentamos o conteúdo da décima questão da AAP de 2013, desenvolvida para alunos da $1^{\text {a }}$ série do Ensino Médio, conforme conteúdo do 'Quadro 4':

Quadro 4: Análise da terceira questão

Em uma lanchonete o preço do sanduíche com um refrigerante é $R \$ 11,50$. Lucia comeu dois sanduíches e três refrigerantes e pagou $R \$ 26,50$. Quanto pagou Ana que comeu três sanduíches e dois refrigerantes nessa mesma lanchonete?

Fonte: [14] (p. 28)

Os comentários e recomendações pedagógicas extraídas do material desenvolvido para quinta edição da Avaliação de Aprendizagem em Processo em relação ao conteúdo 'Sistemas de equações lineares' concebem os mesmos como

uma ferramenta importante para a resolução de situações-problema contextualizadas. A descrição de alguns contextos permite que sejam escritas as equações e que, ao final, após a resolução do sistema, os valores encontrados para as incógnitas sejam avaliados à luz do contexto inicialmente proposto. [14] (p. 28).

Tendo em vista que a habilidade requerida é resolver situações-problema por intermédio de sistemas de equações lineares, é desejável que os procedimentos de resolução contemplem os métodos estudados no Ensino Fundamental, ou seja, o método da adição ou substituição. 
A habilidade requerida para esta questão na AAP [14] está compatível com a prescrição no estudo e avaliação de sistemas lineares de duas equações do $1^{\circ} \mathrm{grau}$ com duas variáveis no $8^{\circ}$ ano do Ensino Fundamental via Caderno do Professor e Matriz Processual de Avaliação. Por esses documentos, é possível o aluno escolher o procedimento algébrico que achar mais adequado para obter a solução do sistema. Vale ressaltar que no Caderno do Professor, há a orientação de que o aluno seja motivado a verificar se a solução encontrada para o sistema linear está correta.

Em termos de resolução, vamos adotar as seguintes incógnitas: " $x$ " (preço do sanduíche) e " $y$ " (preço do refrigerante). O sistema de equações lineares é composto pelas equações $x+y=11,50$ e $2 x+3 y=26,50$. A resolução do referido sistema deve gerar os seguintes resultados: $x=\mathrm{R} \$ 8,00$ e $y=\mathrm{R} \$ 3,50$. Por fim, o gasto de Ana é dado por 3. $(8)+2 .(3,5)=\mathrm{R} \$ 31,00$.

Na conversão de representação semiótica dos registros na língua materna para o algébrico, o primeiro critério de congruência não é conservado por causa da estrutura da segunda equação do $1^{\circ}$ grau com duas incógnitas. Na frase 'Lucia comeu dois sanduíches e três refrigerantes e pagou $R \$ 26,50$ ', o preço pago por dois sanduíches implica uma equivalência referencial algébrica formada por três signos, ou seja, '2. $x$ '. Mesma situação ocorre para o preço de três refrigerantes, cuja equivalência referencial algébrica demanda três signos, ou seja, ' $3 . y$ '.

Em cada uma das duas equações que compõem o sistema linear, cada unidade significante da representação semiótica no registro de saída (língua materna) tem uma única unidade na outra representação semiótica do registro de chegada (algébrico), o que valida o segundo critério de congruência.

A validade se faz presente também no terceiro critério de congruência, pois a ordem das unidades de significado nas duas equações é conservada na transformação de conversão da representação semiótica no registro da língua materna para a representação semiótica no registro algébrico.

Em comparação às duas primeiras questões analisadas, essa questão é a que apresenta o menor custo cognitivo, pois apenas o primeiro critério de congruência semântica não é conservado.

\subsection{Quarta questão}

A primeira questão da AAP de 2014 para o 9 o ano do Ensino Fundamental compõe o repertório submetido a análise, conforme 'quadro 5': 
Quadro 5: Análise da quarta questão

Numa balança, como representada abaixo, foram colocados objetos de maneira que a balança ficou em equilíbrio.

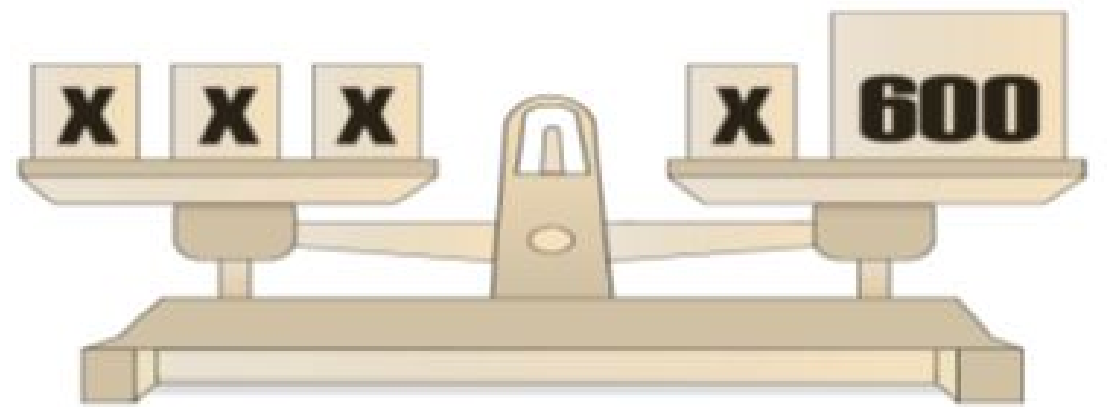

Se a letra x representa o peso do objeto conforme a figura, para que o prato da esquerda tenha o mesmo peso do prato da direita o valor de $x$ deve ser:

Fonte: [14] (p. 28)

A habilidade requerida para essa questão é "saber expressar de modo significativo a solução" da equação do $1^{\circ}$ grau [16] (p. 5). De acordo com os comentários e recomendações pedagógicas dessa AAP, a expressão "modo significativo" se concretiza quando o aluno compreende a analogia entre a equação e o uso da balança com pratos.

"O objetivo dessa questão é identificar se o aluno percebe tal analogia e que, retirando-se o objeto de peso $x$ de ambos os pratos, ainda o equilíbrio se mantém. Assim, se obtém que 2 objetos de peso $x$ pesam $600 \mathrm{~g}$, donde se conclui que cada um pesa 300 g" [16] (p. 5).

Os procedimentos expostos na resolução denota uma transformação de conversão da representação semiótica entre o registro figural (esquema de balança) e o registro algébrico, de forma congruente, por conta da visibilidade direta na transição e mobilização entre registros.

A transformação de tratamento da representação semiótica no registro algébrico possibilita obter $300 \mathrm{~g}$ como o peso requerido para o objeto.

Não há compatibilidade da habilidade descrita para esta questão quando comparada com a Matriz de Avaliação Processual e o Caderno do Professor. Nesses documentos valoriza-se a transposição de linguagens (do texto para a Álgebra e vice-versa), como competência e habilidade no estudo de Equação do $1^{\circ}$ grau.

\subsection{Quinta questão}

O conteúdo da décima questão da AAP de 2014 para o $9^{\circ}$ ano do Ensino Fundamental é objeto de estudo em nossa pesquisa, conforme conteúdo do 'Quadro 6': 
Quadro 6: Análise da quinta questão

Num supermercado um pacote com 6 barras de cereal custa 7 reais a mais que uma barra de cereal. Determine o preço de uma barra de cereal.

\section{Fonte: São Paulo [16] (p. 21)}

A habilidade requerida nessa questão via AAP é compatível com a Matriz de Avaliação Processual e o Caderno do Professor, nos quais o aluno de ser capaz de "saber expressar de modo significativo a solução de equações" do $1^{\circ}$ grau [16] (p. 21). Na grade de correção contida nessa edição da AAP, "a resposta correta é $R \$ 1,40$. $O$ aluno consegue obter a expressão matemática para o problema: $6 x=x+7$ e resolve corretamente obtendo $x=7 / 5=1,4 "$ [16] (p. 21).

Na transformação de conversão de representação semiótica dos registros na língua materna para o algébrico, o primeiro critério de congruência não é conservado, pois o 'custo' de uma barra de cereal denotado por ' $x$ ' tem um signo e quando associado ao custo de seis barras de cereais, demanda dois signos, ou seja, '6.x'.

Porém, nessa questão verificamos tanto a conservação da univocidade semântica terminal quanto a conservação da ordem das unidades de significado, pois entendemos que há uma equivalência entre o custo de 'um pacote com 6 barras de cereal' e o custo de '7 reais a mais que uma barra de cereal', ou seja, $6 x=7+x$.

O custo cognitivo nessa atividade cognitiva de conversão pode ser menor ainda, se for proposto uma reformulação no enunciado original (tratamento no registro língua materna), de modo a conservar o primeiro critério de congruência. Uma possibilidade de reescrever o conteúdo desse registro segue: 'Num supermercado o custo do pacote com 6 barras de cereal é o mesmo que o custo de uma barra de cereal acrescido de 7 reais. Determine o preço de uma barra de cereal'.

\subsection{Sexta questão}

O conteúdo da sexta questão foi extraído da 13ª edição da AAP de 2016, aplicada para o $8^{\circ}$ ano do Ensino Fundamental, de acordo com a exposição no 'Quadro 7':

Quadro 7: Análise da sexta questão

Carlos e Marisa compraram canetas "marca texto" e canetas comuns de diversas cores. As canetas "mar-
ca texto" custaram mais que as comuns. Carlos comprou duas canetas de cada tipo, gastando R $\$ 8,20$ e
Marisa comprou 3 canetas "marca texto" e uma caneta comum, gastando R $\$ 9,10$.
Ao equacionar a compra de Marisa e Carlos em um sistema, de forma que $x$ representa as canetas "marca
texto" e $y$ as canetas comuns, temos: $2 x+2 y=8,20$ e $3 x+y=9,10$.
O valor de cada caneta "marca texto" e de cada caneta comum é:

Fonte: São Paulo [17] (p. 24)

A habilidade requerida nesta questão, de acordo com a edição da AAP, é "resolver sistemas de equações lineares" [17] (p. 24) e está compatível com a prescrição no 
estudo e avaliação de sistemas lineares de duas equações do $1^{\circ}$ grau com duas variáveis via Caderno do Professor e Matriz Processual de Avaliação. Porém, conforme já destacamos na análise da terceira questão neste relato de pesquisa, no Caderno do Professor, há a orientação de que o aluno seja motivado a verificar se a solução encontrada para o sistema linear está correta.

Em termos de registro de representação semiótica, o enunciado apresenta a representação semiótica do objeto matemático em dois registros distintos; a língua materna e o registro algébrico. Em termos de atividade matemática, é requerido do aluno o tratamento da representação semiótica no registro algébrico, por meio de cálculos adequados para obter o resultado das duas incógnitas em questão.

\subsection{Sétima questão}

A sétima questão em análise pertence à $21^{\mathrm{a}}$ edição da AAP de 2018 para o $8^{\circ}$ ano do Ensino Fundamental, conforme 'Quadro 8':

\section{Quadro 8: Análise da sétima questão}

Os gráficos a seguir correspondem a representações de três sistemas de equações lineares.

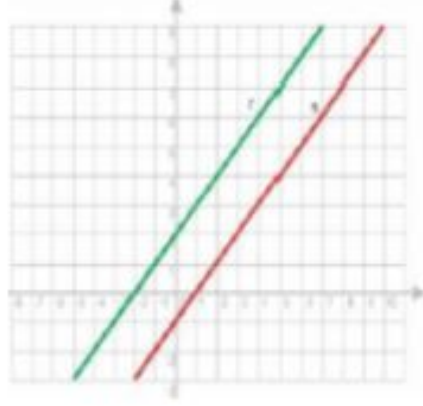

।

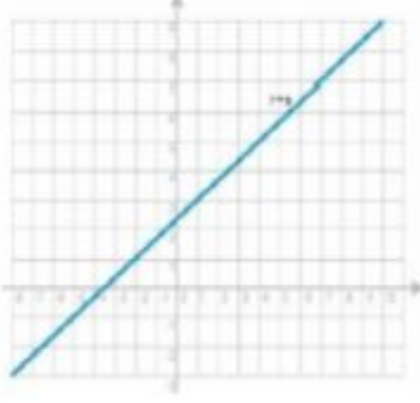

॥

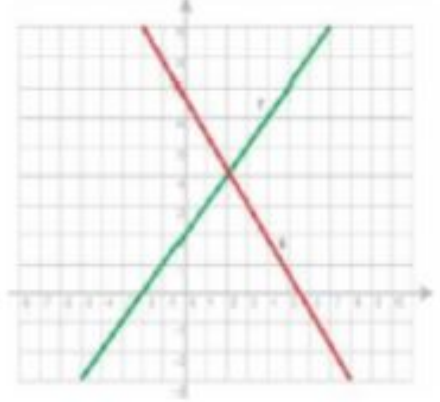

III

Pela análise dessas representações podemos afirmar que esses sistemas são, respectivamente:

Fonte: [19] (p. 26)

No segundo volume do Caderno do Professor para o $8^{\circ}$ ano do Ensino Fundamental, a orientação didático-pedagógica inicial é que os alunos se apropriem dos procedimentos de resolução de um sistema linear formado por duas equações do $1^{\circ} \mathrm{grau}$ com duas variáveis, independente do método escolhido para a resolução. De posse desta competência e habilidade, passa-se a problematizar a questão das possíveis soluções de um sistema linear atrelada à sua representação gráfica. Isto é importante para que o aluno seja capaz de classificar um sistema linear de acordo com o tipo de solução resultante [15].

Nesse processo é recomendável que o professor estimule seus alunos a investigar a posição relativa de duas retas nas representações gráficas e estabelecer a classificação do sistema de equações lineares, de acordo com o 'quadro 9': 
Quadro 9: Classificação dos sistemas de equações lineares

\begin{tabular}{|c|c|c|}
\hline Tipo & Posição relativa de duas retas & Número de solução \\
\hline possível e determinado & Retas concorrentes & uma \\
\hline possível e indeterminado & Retas paralelas coincidentes & infinitas \\
\hline impossível & Retas paralelas disjuntas & nenhuma \\
\hline
\end{tabular}

Fonte: arquivo da pesquisa

Tais habilidades estão em consonância com a habilidade prescrita na AAP e na Matriz de Avaliação Processual, na qual destaca-se que o aluno deve ser capaz de "interpretar graficamente a solução de um sistema linear" [18] (p. 28).

Em termos de registros de representação semiótica, a resolução dessa questão envolve a atividade cognitiva de tratamento da representação semiótica no registro gráfico que, de acordo com [4], consiste na análise da variável visual, no caso, relativa à posição das retas e sua respectiva solução. O conteúdo do 'quadro 9' apresenta de forma ordenada a nomenclatura das posições dos pares de retas apresentadas nessa questão, a classificação do sistema de equações lineares de acordo com o respectivo número de soluções.

\subsection{Oitava questão}

Essa última questão também foi extraída da $21^{\text {a }}$ primeira edição da AAP de 2018 para o $8^{\circ}$ ano do Ensino Fundamental, conforme conteúdo do 'quadro 10':

Quadro 10: Análise da sétima questão

A representação gráfica de um sistema de equações lineares é apresentada a seguir.

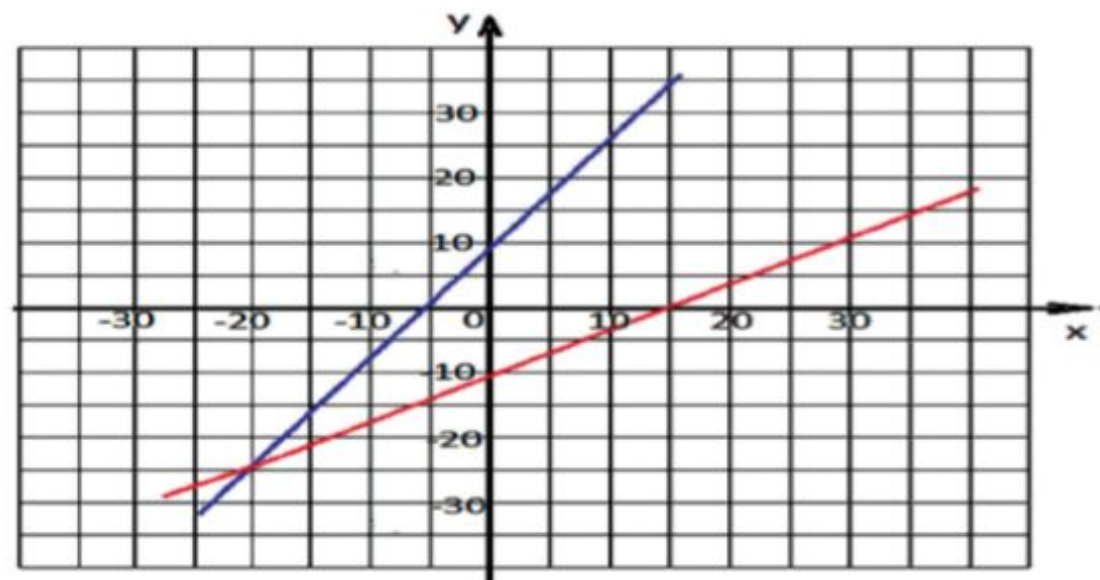

A solução deste sistema é dada por:

Fonte: [19] (p. 28)

Para o aluno ter êxito na resolução dessa questão e obter como resposta o par ordenado $(-20,-25)$, ele deve "reconhecer o significado da representação gráfica de um sistema e identificar o cruzamento das retas como sua solução" [19] (p. 29). Neste caso, associar que as duas retas concorrentes geram a solução $(-20,-25)$, por ser o ponto de intersecção. Essa habilidade converge com a habilidade prescrita na AAP 
e na Matriz de Avaliação Processual, conforme menção feita na análise da questão anterior.

Em relação aos Sistemas de equações lineares é necessário estender aspectos abordados na análise da sétima questão, em relação à representação gráfica que, segundo [4], pode ser abordada a partir da atividade cognitiva de tratamento, tomando por base a interpretação global de propriedades figurais. A interpretação global pressupõe que não há como partir do registro gráfico para o algébrico tomando como referência valores particulares, mas por meio da identificação das variáveis visuais pertinentes.

A variável visual em relação ao registro gráfico nessa questão envolveu a relação da posição das retas (retas concorrentes) e sua solução única (ponto de intersecção entre duas retas).

\section{CONSIDERAÇÕES FINAIS}

Um dos objetivos deste relato de pesquisa foi a contribuição dos registros de representação semiótica na análise de questões da Avaliação da Aprendizagem em Processo. Neste sentido, destacamos aspectos tanto da atividade cognitiva de tratamento quanto da conversão da representação semiótica entre registros.

Em relação ao tratamento, cuja transformação da representação semiótica se efetua no interior de um mesmo registro, houve a análise das variáveis visuais no estudo de sistemas de equações lineares, no registro gráfico presente na sétima e oitava questão. A mobilização de apenas um registro de representação semiótica, no caso o algébrico, foi alvo de análise no conteúdo da sexta questão.

Na atividade cognitiva de conversão da representação semiótica, no estudo do conteúdo 'Equação do $1^{\circ}$ grau', preservou-se o fenômeno da congruência na transição e coordenação entre os registros figural (esquema de balança) e algébrico, na análise do conteúdo da quarta questão. No entanto, a conversão exigida na resolução dessa questão bem como nas demais, considerou-se apenas um sentido, não houve preocupação com o caminho inverso. Isto é de fundamental importância na teoria dos Registros de Representação Semiótica, pois na transição e mobilização da representação semiótica entre registros de partida e chegada ou vice-versa, o custo cognitivo não é o mesmo.

Na quinta questão não houve a conservação do primeiro critério de congruência (correspondência semântica entre as unidades de significado) na análise entre os registros língua materna e algébrico.

O estudo dos 'Sistemas de equações lineares' na atividade cognitiva de conversão da representação semiótica, entre registros língua materna e algébrico, envolveu a análise das três questões iniciais. Apenas a terceira questão apresentou o menor 
custo cognitivo, por conta de apenas um critério de congruência (primeiro) não ter sido conservado.

Nas duas primeiras questões o custo cognitivo foi maior por conta de dois critérios de congruência não terem sido conservados. Em comum, nessas duas questões foi a não conservação do terceiro critério, (ordem das unidades de significado), importante quando se trata de comparar enunciados na língua materna e expressões algébricas. Tal situação nos traz indícios de necessidade de atenção, por parte do professor, para este tipo de critério da não congruência, pois o mesmo pode contribuir em obstáculos para a aprendizagem dos alunos.

O outro objetivo deste relato de pesquisa foi confrontar as habilidades expostas para a resolução de cada uma das questões extraídas de edições da Avaliação de Aprendizagem em Processo - AAP, no período de 2012 a 2018, com as diretrizes expostas no Caderno do Professor e na Matriz de Avaliação Processual para o $8^{\circ}$ ano do Ensino Fundamental. A única divergência na comparação entre essas três fontes documentais foi em relação ao conteúdo da quarta questão analisada. Enquanto a analogia entre a equação e o uso da balança com pratos faz parte das habilidades prescritas na AAP sobre a avaliação do desempenho dos estudantes em 'Equação do $1^{\circ}$ grau', nas demais fontes documentos há uma valorização do aluno ser capaz em fazer uma transposição entre linguagens, ou seja, do texto para a Álgebra e vice-versa.

Cumprido o objetivo para este relatório de pesquisa enfatizamos a importância da ocorrência de análise por parte do professor da educação básica, quanto aos conteúdos propostos em avaliação de larga escala, pois as mesmas tem-se consolidado como um instrumento do processo ensino-aprendizagem em diferentes contextos escolares. A teoria dos registros de representação semiótica constitui um aporte teórico profícuo na análise de fontes documentais, como ocorreu nessa pesquisa pela sua hipótese fundamental de que a compreensão matemática do objeto matemático perpassa pela mobilização de diferentes representações semióticas que, no caso, envolveu o registro algébrico, língua materna, gráfico, numérico e figural. Acrescenta-se a isso, a coordenação das representações semióticas através das suas atividades cognitivas de transformação, ou seja, tratamento e conversão; bem como a análise da congruência semântica.

\section{REFERÊNCIAS}

[1] Brasil. Ministério da Educação. Parâmetros Curriculares Nacionais: Matemática (Ensino Fundamental II). Brasília: MEC/SEF, 1998. 148p.

[2] R. Duval. Registros de representações semióticas e funcionamento cognitivo da compreensão matemática. In: S. D. A. Machado (org.) Aprendizagem em matemática: registros de representação semiótica. Campinas: Papirus, 2003. p.11-33.

[3] R. Duval. Semiósis e pensamento humano: registro semiótico e aprendizagens intelectuais (Sé- 
miosis et PenséeHumaine: Registres Sémiotiques et ApprentissagesIntellectuels). Tradução de L.F.Levy e M.R. A. da Silveira. São Paulo: Editora Livraria da Física, fascículo I, 2009.

[4] R. Duval. Gráficos e equações: a articulação de dois registros. Tradução de M.T. Moretti. Revemat, Florianópolis, v. 6, n. 2, p. 96-112, 2011.

[5] K.O. Franco. Sistema Mineiro de Avaliação da Educação Pública (SIMAVE): o estado da arte da produção científica brasileira (2000-2013). 2016. 161f. Dissertação (Programa de Pós-Graduação em Educação). Campinas: Pontifícia Universidade Católica de Campinas, 2016.

[6] A.C. Gil. Métodos de Pesquisa Social. São Paulo: Atlas, 2008.

[7] E.H. Lourenço; P.C. Oliveira. Congruência semântica e equivalência referencial em problemas envolvendo equações de $1^{\circ}$ grau. Educação Matemática e Pesquisa, São Paulo, v.20, n.1, pp. 84-109, 2018. [CrossRef]

[8] C. Machado; O.M. Alavarse; P.H. Arcas. Sistemas estaduais de avaliação: interfaces com qualidade e gestão da educação. Revista Brasileira de Política e Administração da Educação (RBPAE), Brasilia, v.31, n. 3, p. 667-680, 2015. [CrossRef] [Google Scholar]

[9] M.I.R. Ortigão; M.J.C. Santos; C.A. Aguilar Junior. Pesquisa em avaliação: algumas reflexões. Boletim GEPEM, Seropédica, n.70, pp. 70-89, 2017. [CrossRef]

[10] C.I. Santos, P.C. Oliveira. Avaliação externa em matemática: análise de teses e dissertações que abordam conteúdos matemáticos. Revista Brasileira de Iniciação Científica, Itapetininga v. 7, n. 3 (2020) p.36-55. [Google Scholar]

[11] São Paulo. Secretaria da Educação. Currículo do Estado de São Paulo: Matemática e suas tecnologias - Ensino Fundamental (Ciclo II) e Ensino Médio. Coordenação de área: Nilson José Machado. $1^{a}$ ed. atual. São Paulo, SE, 2012. 72p.

[12] São Paulo. Secretaria da Educação. Avaliação da Aprendizagem em Processo: comentários e recomendações pedagógicas da prova de matemática. São Paulo: SE, 2012, $2^{\circ}$ semestre, $1^{a}$ série $\mathrm{EM}, 3^{\mathrm{a}}$ edição.

[13] São Paulo. Secretaria da Educação. Avaliação da Aprendizagem em Processo: comentários e recomendações pedagógicas da prova de matemática. São Paulo: SE, 2012, $1^{\circ}$ semestre, $2^{\mathrm{a}}$ série $\mathrm{EM}, 2^{\mathrm{a}}$ edição.

[14] São Paulo. Secretaria da Educação. Avaliação da Aprendizagem em Processo: comentários e recomendações pedagógicas da prova de matemática. São Paulo: SE, 2013, $2^{\circ}$ semestre, $1^{\text {a }}$ série EM, $5^{a}$ edição.

[15] São Paulo. Secretaria da Educação. Material de apoio ao Currículo do Estado de São Paulo Caderno do Professor: $8^{\circ}$ ano do Ensino Fundamental, Matemática. São Paulo: SE, 2014-2017, v.2.

[16] São Paulo. Secretaria da Educação. Avaliação da Aprendizagem em Processo: comentários e recomendações pedagógicas para a prova de matemática. São Paulo: SE, 2014, $1^{\circ}$

[17] São Paulo. Secretaria da Educação. Avaliação da Aprendizagem em Processo: Caderno do Professor - Matemática. São Paulo: SE, 2016, $3^{\circ}$ bimestre, $8^{\circ}$ ano EF, $13^{a}$ edição.

[18] São Paulo. Secretaria da Educação. Matriz de avaliação processual: matemática; encarte do professor. Coordenação de G.T. Silveira; R.A.R Santiago. São Paulo: SE, 2016.

[19] São Paulo. Secretaria da Educação. Caderno do Professor: Avaliação da Aprendizagem em Processo- Matemática. São Paulo: SE, 2018, $3^{\circ}$ bimestre, $8^{\circ}$ ano EF, $21^{a}$ edição.

[20] C.R. Soares. Sistemas de avaliações em larga escala na perspectiva histórico-cultural: o caso do Sistema Mineiro de Avaliação da Educação Pública - SIMAVE, dissertação de mestrado, Mestrado Profissional em Educação Matemática, Universidade Federal de Juiz de Fora, 2011. 


\section{BREVE BIOGRAFIA}

Gladys Beatriz Churata Garcia (D) https://orcid.org/

0000-0001-7894-5117

Mestre em Ensino de Ciências Exatas pela Universidade Federal de São Carlos.

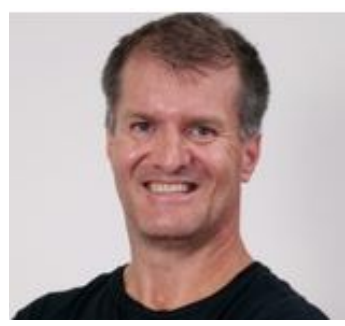

Paulo Cesar Oliveira (D) https://orcid.org/0000-0003-2514-904X

Professor associado da Universidade Federal de São Carlos (campus Sorocaba). Doutor (2003) em Educação Matemática (UNICAMP). Professor da UFSCar e do Programas de Pós-Graduação em Ensino de Ciências Exatas - PPGECE e do Mestrado Profissional em Matemática - PROFMAT em que atua como Vice-Coordenador. Líder do Grupo de Estudos e Planejamento de Aulas de Matemática - GEPLAM (www.geplam.ufscar.br). 